\title{
Semaphorin3D Guides Retinal Axons along the Dorsoventral Axis of the Tectum
}

\author{
Yan Liu, ${ }^{1}$ Jason Berndt, ${ }^{1,2}$ Fengyun Su, ${ }^{3}$ Hiroshi Tawarayama, ${ }^{4}$ Wataru Shoji, ${ }_{4}^{4}$ John Y. Kuwada, ${ }^{3}$ and Mary C. Halloran ${ }^{1,2}$ \\ ${ }^{1}$ Departments of Zoology and Anatomy and ${ }^{2}$ Neuroscience Training Program, University of Wisconsin, Madison, Wisconsin 53706, ${ }^{3}$ Department of \\ Molecular, Cellular, and Developmental Biology, University of Michigan, Ann Arbor, Michigan, 48109-1048, and 4nstitute of Development, Aging, and \\ Cancer, Tohoku University, Sendai 980-8575, Japan
}

We examined the role of Sema3D, a semaphorin of previously unknown function, in guiding retinal ganglion cell (RGC) axons to the optic tectum in the developing zebrafish. Sema3D is expressed more strongly in the ventral versus dorsal tectum, suggesting that it may participate in guiding RGC axons along the dorsoventral axis of the tectum. Ubiquitous misexpression of Sema3D in transgenic zebrafish inhibits ventral but not dorsal RGC axon growth. In addition, ventral RGC axons avoid or stop at individual cells misexpressing Sema3D along their pathway. Sema3D ubiquitous misexpression at later stages also causes ventral RGC axon arbors to spread more widely along the dorsoventral axis of the tectum. Knock-down of Sema3D with morpholino antisense causes ventral RGC axons to extend aberrantly into the ventral tectum. These results suggest that Sema3D in the ventral tectum normally acts to inhibit ventral RGCs from extending into ventral tectum, ensuring their correct innervation of dorsal tectum.

Key words: semaphorin; neuropilin; retinal axon guidance; retinotectal; transgenic zebrafish; topographic map

\section{Introduction}

During development, retinal ganglion cell (RGC) axons grow from the eye to their target, the optic tectum in lower vertebrates, and form a topographic map of visual space. RGCs along the nasal-temporal retinal axis connect to locations along the posteroanterior axis of the tectum. Axons along the dorsoventral retinal axis map along the ventrodorsal (or lateromedial) axis of the tectum. Extensive research has been directed at understanding the molecular mechanisms underlying map formation (Goodhill and Richards, 1999; O'Leary et al., 1999). A number of studies showed that ephrinAs and their receptors, EphAs, guide axons along the anteroposterior axis of the tectum (Nakamoto et al., 1996; Monschau et al., 1997; Frisen et al., 1998; Brown et al., 2000; Feldheim et al., 2000; Walkenhorst et al., 2000; Yamada et al., 2001). A novel protein named repulsive guidance molecule is also implicated in guidance along the anteroposterior axis (Stahl et al., 1990; Monnier et al., 2002). Along the dorsoventral axis, RGC axons are guided in part by activity of ephrinBs (Hindges et al., 2002; Mann et al., 2002; McLaughlin et al., 2003).

Semaphorins were originally identified as inhibitory axon

\footnotetext{
Received Sept. 20, 2003; accepted 0ct. 13, 2003.

This work was supported by National Institute of Neurological Disorders and Stroke Grants NS42228 (M.C.H.) and NS36587 (J.Y.K.), American Cancer Society Grant IRG-58-011-43-04 (M.C.H.), and a grant to the University of Wisconsin Medical School under the Howard Hughes Medical Institute Research Resources Program for Medical Schools (M.C.H.). The National Science Foundation supported acquisition of the confocal microscope (Grant NSF9724515 to Jim Pawley, Department of Zoology, University of Wisconsin). We thank Kate Kalil and Chi-Bin Chien for comments and discussions and Wei Li, Jeremiah Paulus, and Aidan Reilly for fish care. We also thank Caroline Brennan for ephrin and Eph probes and David Turner for the CS2-MT vector.

Correspondence should be addressed to Mary C. Halloran, Department of Zoology, University of Wisconsin, 1117 West Johnson Street, Madison, WI 53706. E-mail: mchalloran@facstaff.wisc.edu.

DOI:10.1523/JNEUROSCI.4287-03.2004

Copyright $\odot 2004$ Society for Neuroscience $\quad 0270-6474 / 04 / 240310-09 \$ 15.00 / 0$
}

guidance cues, although recent studies have shown that some can be attractive (Mark et al., 1997; Kolodkin, 1998; Raper, 2000). Neuropilins and plexins form receptors for semaphorins (Chen et al., 1997; He and Tessier-Lavigne, 1997; Kolodkin et al., 1997; Winberg et al., 1998; Takahashi et al., 1999; Tamagnone et al., 1999). To date, there are no functional studies showing semaphorin participation in retinotectal map formation, although the expression patterns of semaphorins and their receptors are consistent with such a role. Neuropilins and plexins are expressed in the retina and/or tectum of Xenopus, chick, and mice (Takagi et al., 1987, 1995; Fujisawa et al., 1990; Kawakami et al., 1996). Furthermore, several semaphorins are expressed in the tectum in zebrafish (Halloran et al., 1998, 1999; Yee et al., 1999), chick (Luo et al., 1995), and Xenopus (Campbell et al., 2001). Xenopus retinal axons express neuropilin and are repelled in vitro by one semaphorin, Sema3A,which is expressed in the tectum (Campbell et al., 2001). These studies suggest that semaphorins may regulate retinotectal development.

Sema3D (semaZ2/collapsin-2) is a secreted semaphorin expressed during development of the nervous system in zebrafish (Halloran et al., 1999) and chick (Luo et al., 1995). We reported previously that zebrafish sema3D is expressed in the ventral tectum (Halloran et al., 1999). Here we show that RGC axons are responsive to and likely guided by Sema3D in vivo. Ubiquitous misexpression of Sema3D in vivo inhibits growth of ventral RGC axons. Furthermore, ventral RGC axons appear to avoid cells along their pathway that locally misexpress Sema3D. Both Sema3D ubiquitous misexpression and morpholino antisense knock-down cause defects in tectal innervation along the dorsoventral axis of the tectum. Our results show that Sema3D may play an important role in the formation of the retinotopic map along the dorsoventral axis of the tectum. 


\section{Materials and Methods}

Animals

Zebrafish (Danio rerio) were maintained in a laboratory breeding colony on a $14 / 10 \mathrm{hr}$ light/dark cycle. Embryos were maintained at $28.5^{\circ} \mathrm{C}$ and staged as described previously (Kimmel et al., 1995). Embryo age is defined as hours post-fertilization (hpf). Embryos were kept in $0.003 \%$ 1-phenyl-2-thiourea after $22 \mathrm{hpf}$ to block pigment formation. For heat induction, embryos were transferred to a $38-39^{\circ} \mathrm{C}$ water bath for $1 \mathrm{hr}$.

\section{Production of transgenic fish}

DNA preparation and injection. To make the sema3D-myc fusion gene, the stop codon of sema3D was removed by PCR, and the sema3D gene was inserted into the ClaI site of the CS2+MT expression vector so that the six myc epitopes were in-frame with the final codon of the sema3D gene. The $1.5 \mathrm{~kb}$ zebrafish $h s p 70$ (heat shock protein 70 ) promoter (Halloran et al., 2000) was inserted into the PstI site of the Clontech (Cambridge, UK) pEGFP-1 promoter reporter vector. The egfp (enhanced green fluorescent protein) gene was removed with SalI and NotI, and the sema3D-myc gene was inserted in its place. Plasmid DNA was prepared with a Qiagen (Hilden, Germany) Maxi-prep kit. Approximately $1 \mathrm{nl}$ of a $50 \mu \mathrm{g} / \mathrm{ml}$ solution of the DNA in $0.1 \%$ phenol red was injected into one blastomere of embryos at the one- to four-cell stage. Injected embryos were raised to maturity, and their offspring were screened with PCR for the presence of the transgene.

PCR screening. DNA was obtained from clutches of 50-200 embryos by extraction in lysis buffer ( $100 \mathrm{~mm}$ Tris- $\mathrm{HCl}$, pH 8.5, 5 mм EDTA, $0.2 \%$ SDS, $200 \mathrm{~mm} \mathrm{NaCl}$, and $100 \mu \mathrm{g} / \mathrm{ml}$ Proteinase $\mathrm{K}$ ) at $55^{\circ} \mathrm{C}$, precipitated, and screened for the presence of the transgene with PCR. The forward primer (CATGTGGACTGCCTATGTTC) was near the $3^{\prime}$ end of the $h s p 70$ promoter sequence, and the reverse primer (GGTTATAGCTGTGCAAAACTC) was near the $5^{\prime}$ end of the sema3D gene. To screen adult transgenic fish, fish were anesthetized in $0.02 \%$ tricaine, and a small piece of caudal fin was clipped. DNA was extracted as above.

\section{Mosaic Sema3D misexpression}

Embryos were injected into the blastomere at the one-cell stage with $\sim 1$ $\mathrm{nl}$ of a $50 \mu \mathrm{g} / \mathrm{ml}$ solution of $h s p 70: s e m a 3 D^{g f p}$ or $h s p 70: g f p$ DNA. DNA was prepared with a Qiagen Maxi-prep kit.

\section{In situ hybridization and immunohistochemistry}

Digoxygenin-UTP-labeled riboprobes for sema3D, npn-1a (neuropilin1a), npn-1b, npn-2a, npn-2b, ephrin-A5, ephrin-A2, ephrin-B2, EphB3, and EphA4 were synthesized by in vitro transcription and hydrolyzed to an average length of 200-500 bases by limited alkaline hydrolysis (Cox et al., 1984). Whole-mount in situ hybridization was performed as described previously (Halloran et al., 1999).

For whole-mount immunohistochemistry, embryos were fixed in $4 \%$ paraformaldehyde overnight, blocked in $5 \%$ sheep serum and $2 \mathrm{mg} / \mathrm{ml}$ BSA in PBS, and incubated in anti-myc clone 9E10 (University of Wisconsin Hybridoma Center, Madison, WI) at 1:5. Antibody labeling was completed with the Vectastain Mouse IgG ABC immunoperoxidase labeling kit (Vector Laboratories, Burlingame, CA).

\section{Morpholino antisense}

Morpholino oligonucleotides against sema3D mRNA were designed and synthesized by Gene Tools (Corvallis, OR). The sequence of the sema3D blocking morpholino (3DMO) is as follows (with the sequence complementary to the start codon underlined): 5'- CATGATGGACGAGGAGATTTCTGCA-3'. The control morpholino (conMO) consisted of the same sequence with four mis-paired bases, shown in lowercase: $5^{\prime}$ CATcATGcACGAGGAGATaTCTcCA-3'. Approximately 3 ng of morpholino oligos were injected into newly fertilized embryos at the one- to four-cell stage as described previously (Nasevicius and Ekker, 2000).

\section{Western blotting}

Embryos were injected at the one-cell stage with 3DMO or conMO. Embryos were raised to $60 \mathrm{hpf}$, heat induced for $1 \mathrm{hr}$, and allowed to recover for $2 \mathrm{hr}$ longer before freezing. Protein extraction and Western blotting were performed with standard techniques. Blots were processed with anti-myc antibody (A14; Santa Cruz Biotechnology, Santa Cruz,
CA) at 1:1000 and HRP-conjugated anti-rabbit IgG (Jackson ImmunoResearch, West Grove, PA) and visualized with chemiluminescence.

\section{DiI-DiA injections and imaging}

To label axons from specific regions of the retina, embryos were fixed in $4 \%$ paraformaldehyde and mounted in $1 \%$ low-melting agarose. A $0.2 \%$ solution of DiI (1,1' -dioctadecyl-3,3,3',3'-tetramethylindocarbocyanine perchlorate) (Molecular Probes, Eugene, OR) or DiA (4-4dihexadecylaminostyryl- $N$-methylpyridinium iodide) in dimethylformamide was pressure injected into the retina. The dye was allowed to transport overnight. Standard fluorescence images were captured on a Nikon (Tokyo, Japan) TE300 inverted microscope equipped with a Spot RT camera (Diagnostic Instruments, Sterling Heights, MI) and processed with the Metamorph software (Universal Imaging Corporation, West Grove, PA). Confocal series were performed on a Zeiss (Oberkochen, Germany) Axiovert 100M microscope with the Bio-Rad (Hercules, CA) 1024 Lasersharp Confocal software package. Step sizes were $1 \mu \mathrm{m}$.

\section{Results}

\section{Expression of sema3D and neuropilins}

To better clarify the role of Sema3D, we examined the expression of sema3D in more detail. sema3D is expressed throughout the ventricular region of the tectum, with highest expression in the ventral tectum, and is expressed in a patchy pattern in the ventral tectal neuropil (Fig. 1A,B) (Halloran et al., 1999). A confocal projection through the tectal neuropil in an embryo labeled with fluorescent in situ hybridization shows the difference in sema3D expression between ventral and dorsal tectum (Fig. $1 B$ ). In addition, sema3 $D$ is expressed at the posterior border of the tectum, in a region not innervated by RGC axons (Fig. $1 B$, arrows).

In chick, Npn-1 binds Sema3D and is likely a component of the Sema3D receptor (Feiner et al., 1997). In zebrafish, four different neuropilins have been identified, $n p n-1 a, n p n-1 b, n p n-2 a$, and $n p n-2 b$ (Lee et al., 2002; Shoji et al., 2003) (H. Tawarayama and W. Shoji, unpublished observations). Zebrafish $n p n-1 a, n p n-$ $1 b$, and $n p n-2 a$ are expressed in the RGC retinal layer when RGC axons are extending. Of these, $n p n-1 a$ expression is strongest and changes with time in a ventral to dorsal pattern. At $36 \mathrm{hpf}$, when RGC axons are in the early stage of outgrowth, $n p n-1 a$ is expressed strongly in ventral retina, in both the nasal and temporal halves but not in dorsal retina (Fig. 1C). By 48 hpf, when RGC axons are arriving at the tectum, $n p n$ - $1 a$ expression is seen in both ventral and dorsal retina (Fig. $1 D$ ). $n p n-1 b$ also shows expression in the ventral but not dorsal retina at $36 \mathrm{hpf}$ and is expressed uniformly in the RGC layer at $48 \mathrm{hpf}$, with weaker expression than $n p n-1 a$ (Fig. $1 E, F$ ). $n p n-2 A$ is expressed more weakly in the RGC layer at $48 \mathrm{hpf}$, with no apparent pattern (Fig. 1G), and is not expressed at $36 \mathrm{hpf} . n p n-2 b$ is expressed in the inner nuclear layer but is not expressed in the RGC layer (Fig. $1 H$ ). Whether all, none, or a subset of RGC axons have functional receptors for Sema3D will depend on the expression pattern of the plexin coreceptor for Sema3D. Because the identity of this plexin is unknown, it is not possible to predict which RGC axons should be responsive to Sema3D at present. However, $n p n$ expression by RGCs does suggest they are sensitive to some class 3 semaphorins.

\section{Generation of transgenic fish}

To investigate the function of Sema3D, we generated transgenic zebrafish containing the sema3D gene tagged with six myc epitope tags at the $\mathrm{C}$ terminus and driven by the zebrafish inducible $h s p 70$ promoter (Halloran et al., 2000). We tested whether the transgene was heat inducible in $h s p 70: s e m a 3 D^{m y c} \mathrm{~F} 1$ offspring using in situ hybridization for sema3D mRNA or antibody labeling of the myc epitope tag after heat induction in F1 embryos (Fig. 2). 

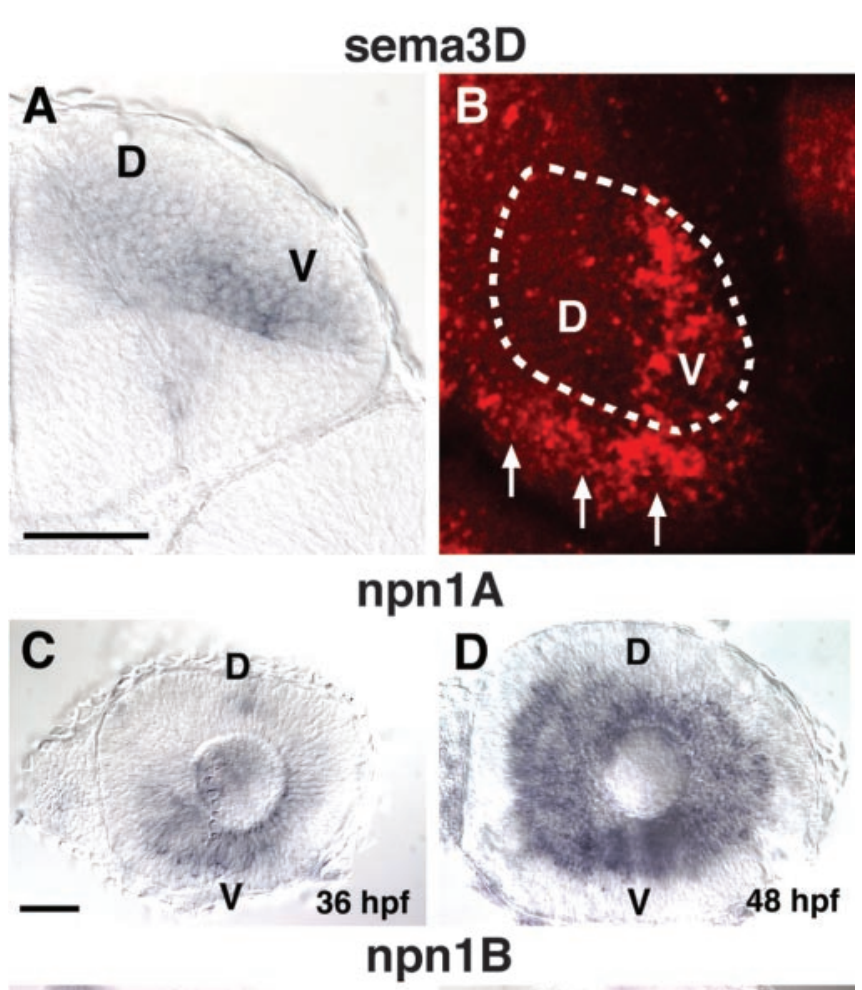

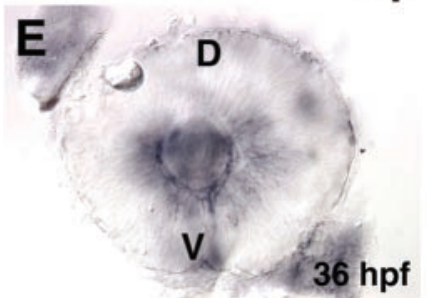

npn2A
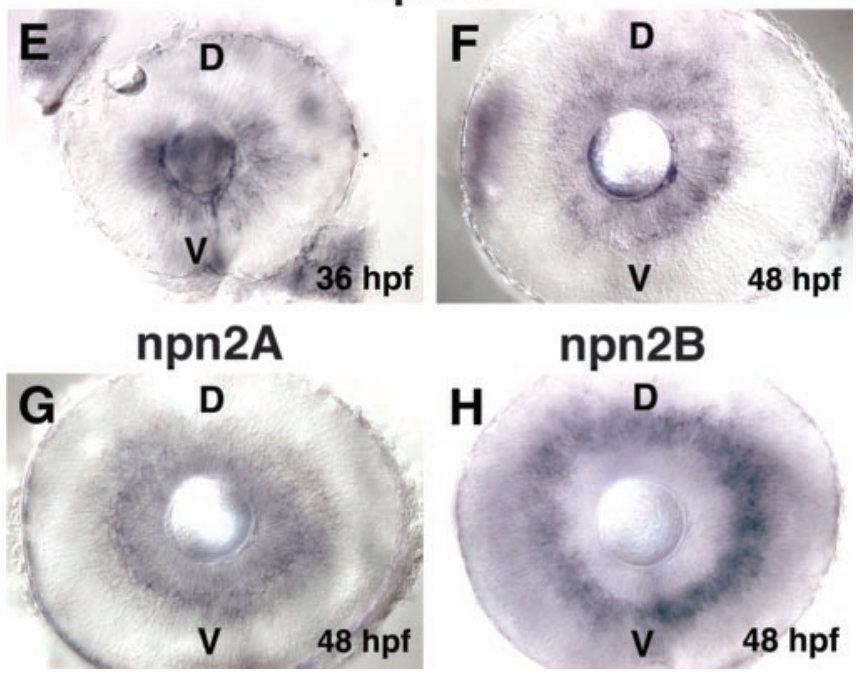

npn2B

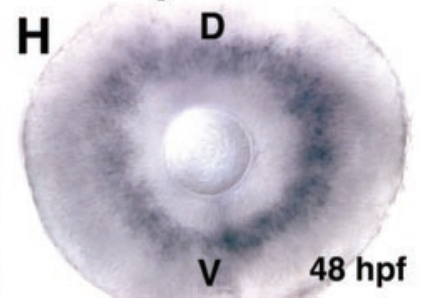

Figure 1. Expression pattern of sema3D and neuropilins. $A$, Cross section through the midbrain (dorsal is up) of $48 \mathrm{hpf}$ embryos showing sema3D in situ hybridization in the right tectum. sema3D mRNA is expressed more strongly in the ventral (V) versus dorsal (D) tectum. B, Dorsal view of right tectum (anterior is up) in $48 \mathrm{hpf}$ embryos showing sema3D in situ hybridization. Fast Red, which fluoresces, was used as the color substrate, and the image is a confocal projection through the tectal neuropil. Approximate domain of tectal neuropil is indicated with dotted line. sema3D expression is visible in ventral tectum $(\mathrm{V})$. Arrows denote sema3D expression at posterior border of tectum. $C, D$, Lateral views of eyes (nasal to left) at $36 \mathrm{hpf}(D)$ and $48 \mathrm{hpf}(E)$ showing npn-1a in situ hybridization. npn-1a expression appears earlier in the ventral (V) retina. $E, F$, Lateral views of eyes at $36 \mathrm{hpf}(E)$ and $48 \mathrm{hpf}(F)$ showing expression of npn-16.G, $n p n-2 a$ expression in RGCs at $48 \mathrm{hpf} . H, n p n-2 b$ expression in inner nuclear layer at $48 \mathrm{hpf}$. Scale bars, $50 \mu \mathrm{m}$.

Transgenic embryos fixed 1-4 hr after heat induction showed strong, widespread misexpression of sema3D mRNA (Fig. 2A,B) and protein (Fig. 2C,D). By $8 \mathrm{hr}$ after heat induction, expression of the transgene had decreased significantly (data not shown). Heat-treated wild-type spawn mates and transgenic embryos that were not heat induced both showed the normal pattern of sema3D expression (Fig. $2 A, C$ ).

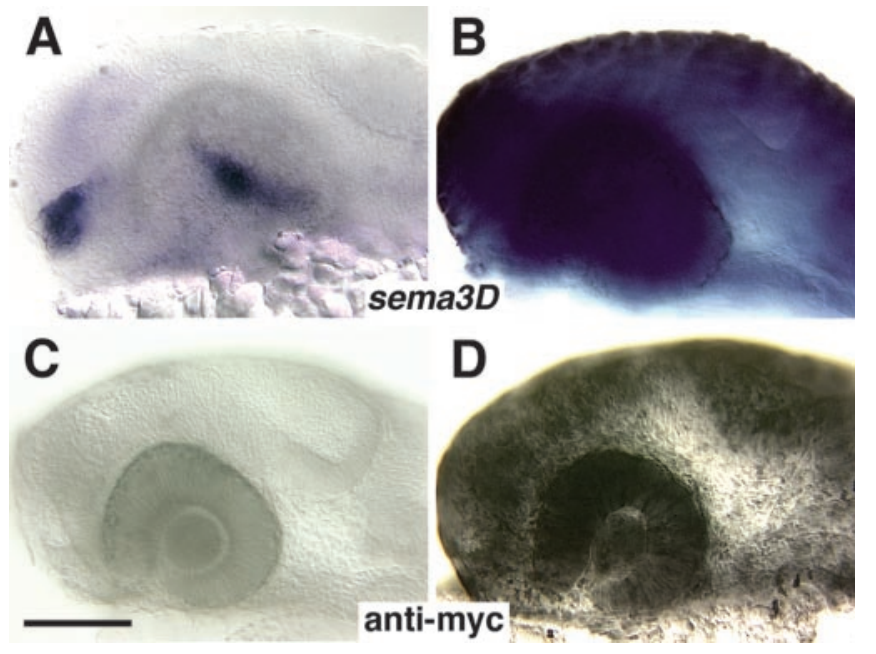

Figure 2. sema3D is inducible in $h s p 70: s e m a 3 D^{m y c}$ transgenic fish. $A-D$, Lateral views (anterior is to the left) of zebrafish embryo head at $1 \mathrm{~d}$ of development. $A, B$, Whole-mount in situ hybridization for sema $3 D 2 \mathrm{hr}$ after heat induction. $A$ is a wild-type embryo showing the normal sema3D expression in two clusters of cells in the diencephalon (blue). Expression in the tectum is not detected at this stage. $B$ is an $h s p 70:$ :sema $3 D^{m y c}$ transgenic embryo showing widespread sema3D expression. C, D, Anti-myc labeling after heat induction. C is a wild-type embryo that shows no myc expression. $D$ is an $h s p 70: s e m a 3 D^{m y c}$ transgenic embryo showing widespread myc expression. Scale bar, $100 \mu \mathrm{m}$.

F1 embryos from nine different founder fish were raised to establish lines. In all of the lines, when a transgenic F1 fish was crossed with a wild-type fish, $50 \%$ of the F2 offspring showed inducible misexpression of sema3 $\mathrm{D}$ throughout the embryo, and in-crosses between transgenic F1 fish resulted in F2 generations with $75 \%$ expressing embryos. These ratios indicate that the transgene segregates in a Mendelian manner and has inserted at a single locus. We also generated lines of fish homozygous for the sema3D transgene, by in-crossing pairs of F2 hemizygous fish. Sema3D misexpression experiments were done with homozygous embryos from two separate transgenic lines to control for any potential integration position effects.

\section{Ubiquitous Sema3D misexpression inhibits ventral retinal RGC axons}

To test the hypothesis that Sema3D guides retinal axons along the dorsoventral axis of the tectum, we asked first whether RGC axons from the ventral versus dorsal retina showed different responsiveness to Sema3D misexpression. In the zebrafish, RGC axons begin extending out of the eye at $\sim 32 \mathrm{hpf}$ and grow out in a staggered manner over an extended time period (Stuermer, 1988; Burrill and Easter, 1995). The first axons to extend come from the ventral-nasal retina, followed by nasal axons, then dorsal axons, and finally temporal axons. We analyzed the effect of Sema3D misexpression on ventral or dorsal RGC axons by heat inducing $h s p 70: s e m a 3 D^{m y c}$ embryos at specific stages of axon out-

\section{Table 1. Definition of retinal pathway regions}

\begin{tabular}{ll}
\hline Region\# & Location of leading axons \\
\hline 1 & Within ipsilateral eye \\
2 & Between ipsilateral eye and midline \\
3 & At midline \\
4 & Between midline and contralateral eye \\
5 & In contralateral diencephalon, below lens of contra eye \\
6 & In contralateral diencephalon, above lens of contra eye \\
7 & Above level of contralateral eye/at contra tectum \\
\hline
\end{tabular}


growth: either at the time of initial outgrowth (30 hpf for ventral axons and $44 \mathrm{hpf}$ for dorsal) or later when axons are crossing the midline or extending toward the contralateral tectum ( $41 \mathrm{hpf}$ for ventral and $48 \mathrm{hpf}$ for dorsal). Embryos were fixed $6 \mathrm{hr}$ after heat induction, and either the ventral or dorsal RGC axons were labeled with a localized injection of DiI into the retina. We defined regions of the retinotectal pathway (Table 1) and scored embryos on the basis of the location of the most advanced axons. These
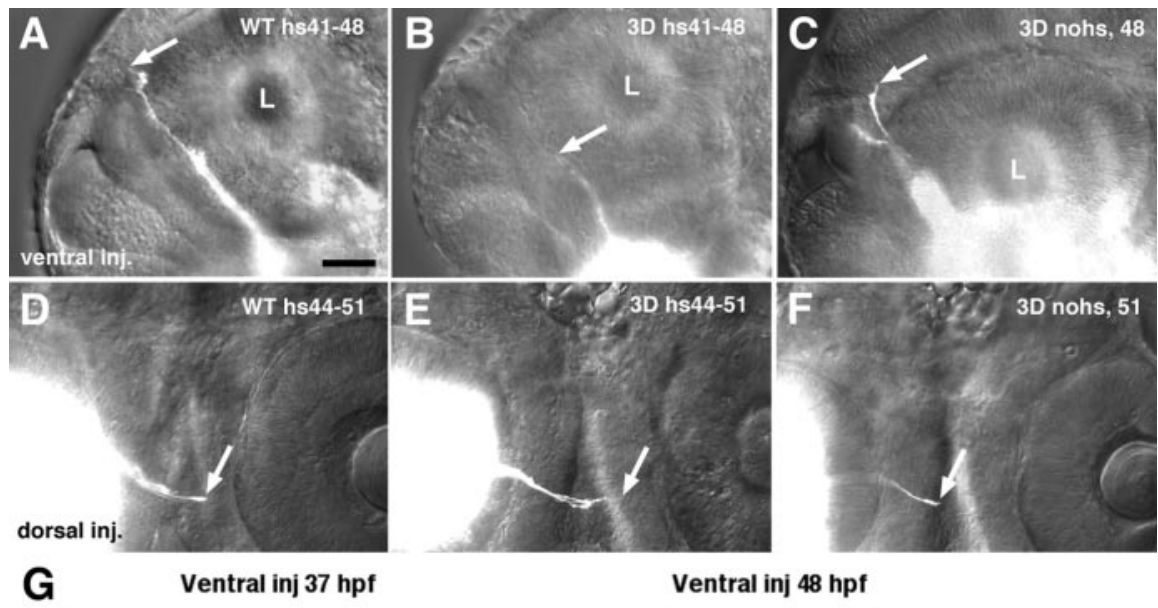

Ventral inj $48 \mathrm{hpf}$

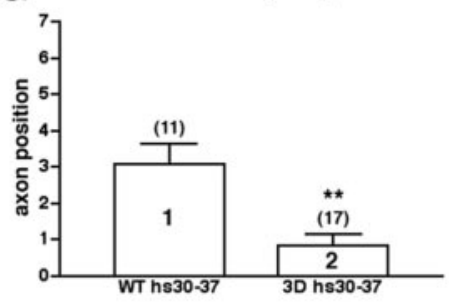

Dorsal inj $51 \mathrm{hpf}$
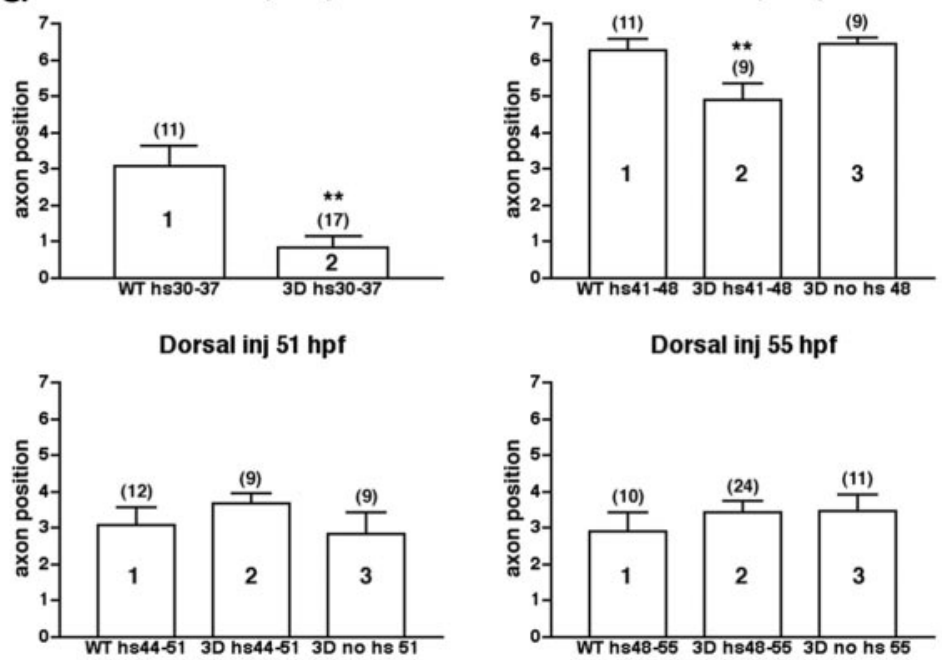

Dorsal inj $55 \mathrm{hpf}$

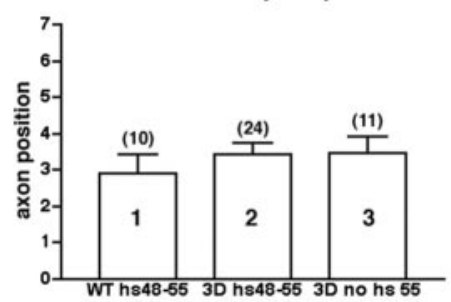

Figure 3. Ventral but not dorsal RGC axons are retarded after Sema3D ubiquitious misexpression. A-C, Lateral views (anterior is to the left) of $48 \mathrm{hpf}$ embryos labeled with Dil injections into ventral retina. Eye on opposite side of embryo is labeled, and axons (white) are shown extending up the contralateral diencephalon. Ventral RGC axons in a wild-type (WT), heat-treated embryo $(A)$ or an hsp70:sema3 $D^{m y c}$ transgenic, nonheated embryo ( $C$ ) have extended to a position in the diencephalon dorsal to the contralateral eye. Ventral axons in a transgenic, heat-induced embryo $(B)$ have only extended to a position in the diencephalon at the level of the ventral one-third of the contralateral eye. Arrows indicate position of axon tips. $L$, Lens of contralateral eye. $D-F$, Ventral views (anterior is to the top) of chiasm region of $51 \mathrm{hpf}$ embryos labeled with Dil injected into dorsal retina. Dorsal axons extend later than ventral and thus have not advanced as far. There is no difference in length of dorsal RGC axons in controls (wild-type heat-treated in $D$ or transgenic nonheat induced in $F$ ) versus transgenic heat-induced embryos $(E)$. Scale bar, $50 \mu \mathrm{m}$. $G$, Bar graphs of mean axon position. Error bars are SEM; values of $n$ are indicated in parentheses. $y$-Axis is axon position as defined in Table 1. Different populations of embryos are distributed along the $x$-axis. Ventral inj $37 \mathrm{hr}$, Ventral retinal injections into wild type (WT) or transgenic (3D) embryos heat induced at $30 \mathrm{hpf}$ and fixed at $37 \mathrm{hpf}$ (hs30-37). ** denotes groups significantly different from others. Groups 1 and 2 are significantly different; $t$ test; $p<0.0008$. At these younger ages, heat induction causes a temporary developmental delay. Thus, nonheated transgenic embryos are not included as a control. Ventral inj $48 \mathrm{hr}$, Ventral retinal injections into wild-type (WT) or transgenic (3D) embryos heat induced at $41 \mathrm{hpf}$ and fixed at $48 \mathrm{hpf}$. 3D no hs 48, Nonheat induced transgenic embryos fixed at $48 \mathrm{hpf}$. Groups 1 and 2 are significantly different; $t$ test; $p<0.0178$. Groups 2 and 3 are significantly different; $t$ test; $p<0.0057$. Dorsal inj $51 \mathrm{hr}$, Dorsal retinal injections into wild-type (WT) or transgenic (3D) embryos heat induced at $44 \mathrm{hpf}$ and fixed at $51 \mathrm{hpf}$. 3D no hs 51, Nonheat induced transgenic embryos fixed at $51 \mathrm{hpf}$. There is no significant difference between any condition. $t$ tests between groups 1 and 2, $p<0.3545$; between 2 and 3,p $<0.1880$. Dorsal inj $55 \mathrm{hr}$, Dorsal retinal injections into wild-type (WT) or transgenic (3D) embryos heat induced at $48 \mathrm{hpf}$ and fixed at $55 \mathrm{hpf}$. 3D no hs 55, Nonheat induced transgenic embryos fixed at $55 \mathrm{hpf}$. There is no significant difference between any condition. $t$ tests between groups 1 and $2, p<0.3996$; between 2 and $3, p<0.9473$. experiments included two controls: heat-treated wild-type emgrowth examined, the growth of ventral RGC axons was dorsal RGC axon outgrowth between control embryos and those dorsal RGC axon outgrowth between control embryos and those ventral RGC axons are inhibited by Sema3D, although dorsal RGC axons are not.

\section{Localized Sema3D misexpression inhibits ventral retinal axons}

In our ubiquitous misexpression experiments, Sema3D is overexpressed in all cells, including the RGCs and cells in their surrounding environment. Therefore, the effects we saw could potentially be attributable to Sema3D overexpression within RGC axons themselves rather than an inhibition from the surrounding tissue. To determine where Sema3D is acting, we analyzed the effects of localized Sema3D misexpression in cells along the pathway of the RGC axons. We injected embryos at the one-cell stage with a DNA construct containing the $h s p 70$ promoter driving expression of a $g f p$-tagged sema3D. DNA injected at the one-cell stage becomes randomly distributed in a mosaic pattern in the embryos. We heat induced the $h s p 70$ : sema3 $D^{g f P}$-injected embryos every $6 \mathrm{hr}$ between 36 and $72 \mathrm{hpf}$ to maintain ectopic Sema3D ${ }^{\text {GFP }}$ expression throughout the stages of RGC axon outgrowth to the tectum, fixed embryos at $75 \mathrm{hpf}$, and injected DiI into the ventral retina. We selected embryos for analysis that had ectopic Sema3D ${ }^{\text {GFP }}$ expression in cells along the RGC axon pathway but not within the DiIlabeled RGCs of the ventral retina (Fig. 4, eyes are shown in insets) $(n=28)$. Embryos injected with $h s p 70: g f p$ DNA and heat induced at the same stages served as controls. In all $h s p 70: g f p$-injected embryos, ventral RGC axons grew into the dorsal tectum and did not alter their pathway when encountering GFP-expressing cells $(n=25)$ (Fig. $4 A, B)$. In contrast, ventral RGC axons in hsp:sema ${ }^{g / P}$-injected embryos stopped at ectopic Sema3D GFP expressing cells (in 11 of 28 embryos) (Fig. $4 D, F)$ or diverted their pathway to avoid the Sema3D ${ }^{\text {GFP }}$-expressing cells (in 7 of 28 embryos) (Fig. 4C,D). In embryos with numerous Sema3D ${ }^{\mathrm{GFP}}$-expressing cells present in the tectum, the RGC axons often did not invade the tectum and did not have visible growth cones, suggesting that they had collapsed and/or retracted (seen in 11 of 28 embryos) (Fig. $4 E$ ). In only 2 of 28 embryos did we see RGC axons that ap- 

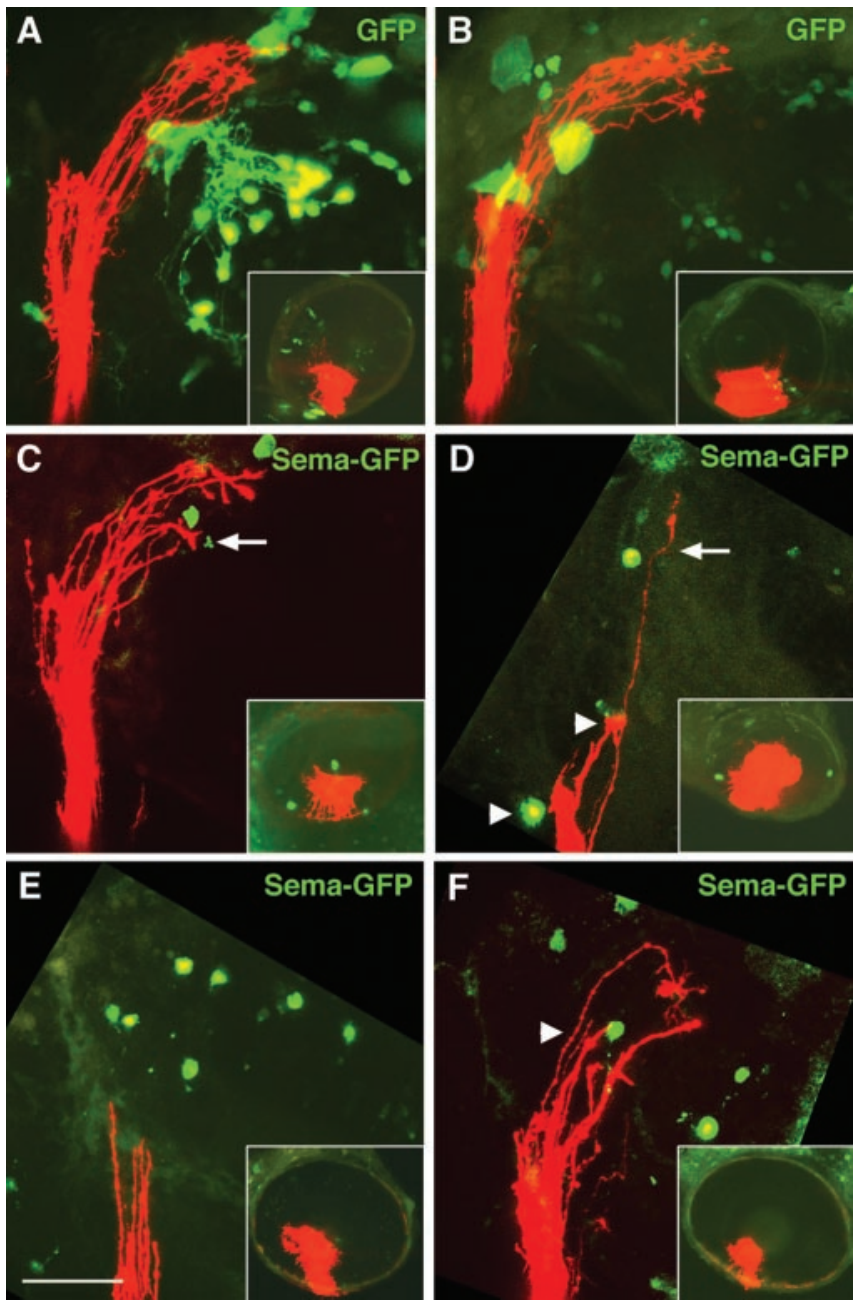

Figure 4. Localized Sema3D misexpression inhibits ventral RGC axons. Lateral views (anterior is to the left; dorsal is to the top) of confocal projections of ventral RGC axons (red) extending into tectum in $75 \mathrm{hpf}$ embryos. Insets show lateral views of injected eye. $A, B$, Embryos injected with control hsp70:gfp DNA. Green cells are expressing GFP. Ventral RGC axons ignore GFPexpressing cells. $C-F$, Embryos injected with $h s p 70: s e m a 3 D^{g f p}$ DNA. Green cells are expressing Sema3D GFP. Axons avoid (arrows in C, D) or stop at (arrowheads in D, F) Sema3D GFP -expressing cells. In $E$, many cells in the tectum are misexpressing Sema3D, the ventral RGC axons are located at the entrance to the tectum, and growth cones appear retracted - collapsed. RGC cell bodies in the retinal injection site are not misexpressing Sema3D ${ }^{\text {GFP }}$ (insets). Scale bar, $50 \mu \mathrm{m}$.

peared to cross directly over a Sema3 $\mathrm{D}^{\mathrm{GFP}}$-expressing cell. In both of these cases, there was only one cell misexpressing Sema3D ${ }^{\text {GFP }}$. These results suggest that Sema3D present in surrounding cells is inhibitory to ventral RGC axons.

\section{Sema3D misexpression causes errors in retinotectal mapping} along the dorsoventral axis

We examined next whether Sema3D ubiquitous misexpression in hsp70:sema3 ${ }^{m y c}$ embryos would disrupt the formation of the retinotectal topographic map at later stages. We performed multiple heat inductions of embryos to overexpress Sema3D at 36 $\mathrm{hpf}$, at $42 \mathrm{hpf}$, and again at $48 \mathrm{hpf}$ and then allowed the embryos to develop until 3-3.5 d post-fertilization (dpf), when RGC axons are innervating the tectum. We labeled discrete regions of the retina by injecting DiI into the ventral retina and DiA into the dorsal retina. We found that ventral retinal axons did not target correctly in embryos misexpressing Sema3D (Fig. 5C-E). Although most ventral RGC axons extended into the appropriate dorsal tectum, their arbors also extended into the ventral tectum, which is not their correct target. Expansion of the ventral RGC axon arbors into the ventral tectum was seen in $69.6 \%$ of embryos $(n=23)$ misexpressing Sema3D (Fig. 5C-E, region of overlap appears yellow). In controls, DiI- and DiA-labeled axon arbors typically were well separated in the tectum and targeted correctly (Fig. $5 B)$, although, in $26.3 \%$ of controls $(n=19)$, we detected a slight overlap that was never as extensive as that seen in Sema3D misexpressing embryos. Dorsal retinal axons were not observed to extend into inappropriate regions of the tectum after Sema3D misexpression. Our results suggest that Sema3D normally regulates the position of ventral RGC axons along the dorsoventral axis of the tectum (see Discussion).

\section{Sema3D knock-down causes errors in retinotectal mapping along the dorsoventral axis}

We analyzed effects of Sema3D loss-of-function by injecting embryos with morpholino antisense oligonucleotides (MO) (Nasevicius and Ekker, 2000; Ekker and Larson, 2001) that block sema3D translation. We used a control MO that consists of the same antisense sequence, except that four bases were changed. To demonstrate the ability of the sema3D antisense MO to block production of Sema3D protein, we injected morpholinos into recently fertilized embryos from one of the homozygous $h s p 70$ : sema $3 D^{m y c}$ transgenic lines. At $60 \mathrm{hpf}$, injected embryos were heat induced, allowed to recover until $63 \mathrm{hpf}$, and then analyzed for the presence of Sema3 ${ }^{\text {myc }}$ by Western blotting with an antibody against the myc epitope tag. We found that myc expression after heat induction was significantly reduced in the sema $3 D$ antisense $\mathrm{MO}$-injected embryos compared with the control MO-injected and uninjected embryos (Fig. $5 F$ ). This result shows that the sema3D antisense $\mathrm{MO}$ can effectively block Sema3D translation and that the inhibition can last at least as late as $63 \mathrm{hpf}$, through the time when the RGC axons are extending into the tectum.

To analyze effects of Sema3D loss-of-function on retinotectal mapping, we injected embryos at the one- to four-cell stage with either sema3D antisense MO or control MO and allowed them to grow until $5 \mathrm{dpf}$, when the retinotectal map is mature. Embryos were injected with DiI into ventral retina and DiA into dorsal retina. In control MO-injected embryos, ventral and dorsal RGC axons extended into their appropriate tectal territories (Fig. 5G). In some sema3D antisense MO-injected embryos, RGC axons made errors en route to the tectum, and, in some cases ( 3 of 21 embryos), the labeled axons had not entered the tectum (data not shown). In embryos in which axons entered the tectum, we saw errors in RGC mapping along the dorsoventral axis by the ventral RGC axons but not the dorsal axons (Fig. $5 H-J$ ). Ventral RGC axons grew into the dorsal tectum but also into the ventral tectum after Sema3D knock-down. The severity of this phenotype was variable but occurred in $72 \%(n=18)$ of embryos. In 2 of 18 embryos, ventral RGC axons mainly grew correctly into the dorsal tectum, with only a few axons invading the ventral tectum (Fig. $5 H$ ). In 5 of 18 embryos, most labeled ventral RGC axons extended into the inappropriate ventral tectum (Fig. 5I,J). In the remaining embryos, the effect was intermediate, with axons extending into both dorsal and ventral tectum. Unlike ventral RGC axons, dorsal RGC axons did not display obvious mapping errors along the dorsoventral axis of the tectum. These results suggest that Sema3D may normally prevent growth of ventral RGC axons into the ventral tectum. 
A

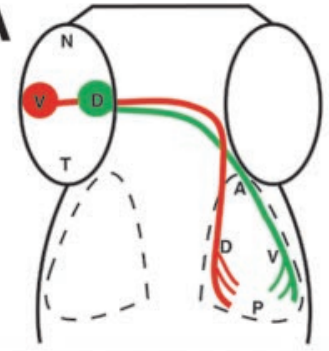

$\mathbf{F}$
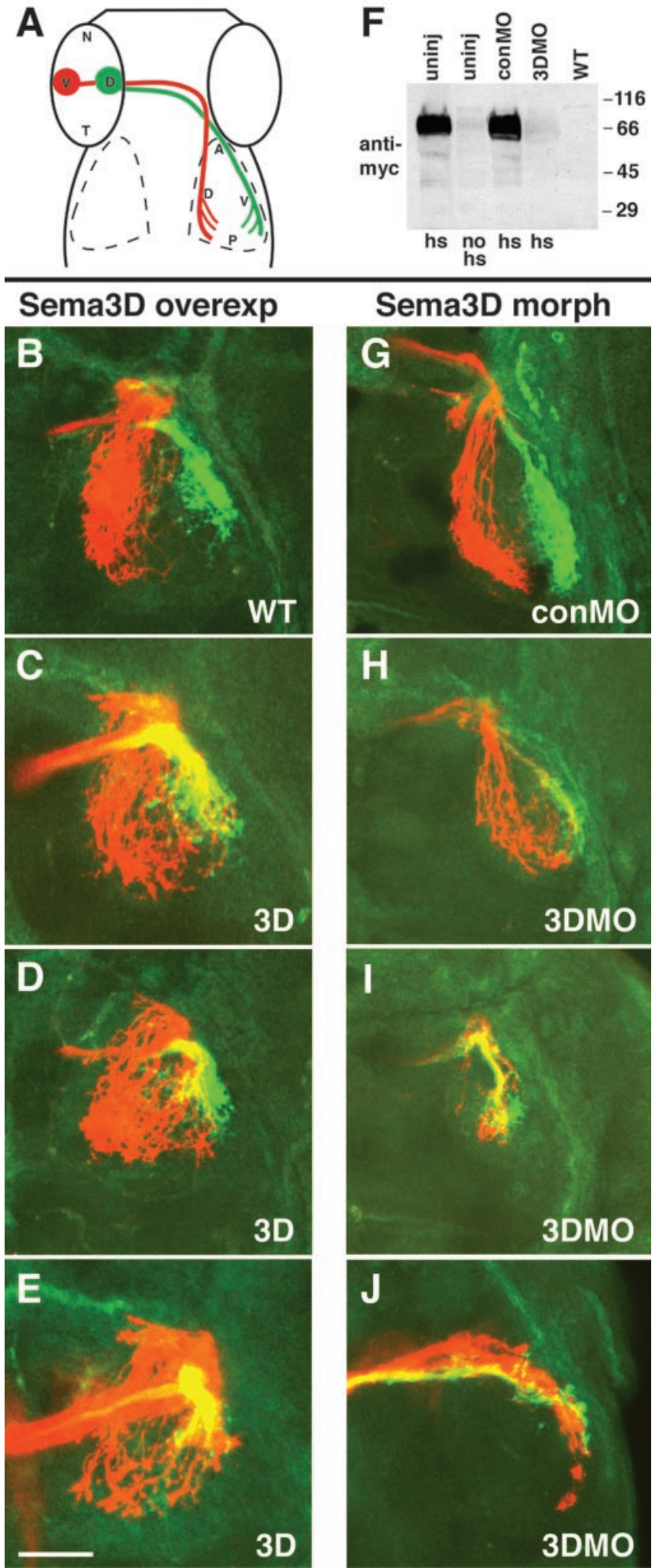

Figure 5. Retinotectal mapping by ventral $\mathrm{RGC}$ axons along the dorsoventral axis is perturbed by misexpression and $M 0$ knock-down of Sema3D. A, Schematic showing injection sites in retina and normal arborization locations. $B-E$, Confocal projections of 3 dpf embryos showing that ventral but not dorsal RGC axons extend aberrantly after misexpression of Sema3D. All are dorsal views (anterior is to the top) of whole-mounted embryos labeled with Dil (red) injection into ventral retina and DiA (green) injection into dorsal retina. Left eyes were injected, and right tectum is shown. Wild-type $(B)$ and hsp70:sema3 $D^{\text {myc }}$ transgenic $(C-E)$ embryos, all heat induced at 36,42 , and $48 \mathrm{hpf}$ and fixed at $3 \mathrm{~d}$. Ventral RGC axons aberrantly extend into ventral tectum after Sema3D overexpression, but the dorsal RGC axons extend normally $(C-E)$. Area of

\section{Patterning of retina and tectum is normal after}

\section{Sema3D manipulation}

The mapping errors by ventral RGC axons after ubiquitous misexpression and knock-down of Sema3D could be a direct result of Sema3D activity on retinal axons or an indirect effect caused by alterations of eye or tectal development. To distinguish between these possibilities, we examined the expression pattern of several developmental markers and other guidance cues after Sema3D overexpression or knock-down. We were particularly interested in the ephrins and their receptors because they are known to guide retinotectal axons and are expressed in specific patterns in the eye and tectum, allowing us to determine whether general eye or tectum polarity has been altered. We examined the expression of ephrinA2, ephrinA5 (Brennan et al., 1997), ephrinB2 (Chan et al., 2001), EphB3, and EphA4 (Xu et al., 1994). We found that the expression patterns of these genes were not altered by either Sema3D misexpression or morpholino knock-down (Fig. 6 and data not shown). After Sema3D knock-down, the eyes and tectum are slightly smaller, but the expression patterns of these genes is unperturbed. Examples of ephrinA5 and ephrinB2 expression after morpholino knock-down are shown in Figure 6. ephrinA5 is expressed in the nasal retina and the posterior tectum, and ephrinB2 is expressed in the dorsal retina and dorsal tectum. These patterns are unaffected by Sema3D knock-down. These results suggest that Sema3D acts directly on growing RGC axons to affect their pathfinding decisions.

\section{Discussion}

Our results show that ventral RGC axons are responsive to Sema3D and provide both loss-of-function and gain-of-function evidence that Sema3D acts to guide retinotectal axons in forming the retinotopic map. We showed that sema3D mRNA is expressed more strongly in the ventral tectum compared with the dorsal tectum. This graded expression of Sema3D makes it a candidate guidance cue for retinotectal mapping along the dorsoventral axis. Zebrafish $n p n-1 a, n p n-1 b$, and $n p n-2 a$, components of the receptor for class 3 semaphorins, are expressed by RGCs during the stages their axons are growing to the tectum, suggesting that RGC growth cones should be responsive to class 3 semaphorins. At early stages of RGC axon outgrowth, $n p n-1 a$ and $n p n-1 b$ are expressed only in the ventral and not dorsal retina; however, at the time RGC axons are innervating the tectum, RGCs throughout the retina express $n p n-1 a$ and $n p n-1 b$. Thus, the molecular basis for our observed effects of Sema3D manipulation on ventral versus dorsal RGC axon guidance cannot be explained only by differential Npn-1 expression. We predict that the plexin component or another unknown component of the Sema3D receptor would be present in a high ventral to low dorsal gradient in the retina throughout the stages of retinotectal map formation. To date, the other components of the Sema3D receptor have not been identified.

overlap between ventral and dorsal RGC axons is yellow. $F$, Western blot showing sema3D antisense M0 knock-down of Sema3D protein expression in hsp70:sema3 $D^{\text {myc }}$ embryos. Lanes 1-4 are hsp70:sema3 ${ }^{m y c}$ embryos. Lane 1, Uninjected, heat induced. Lane 2, Uninjected, not heat induced. Lane 3, conM0 injected, heat induced. Lane 4, 3DM0 injected, heat induced. Lane 5 , Wild type. Blot is processed with anti-myc antibody. $G-J$, Confocal projections of $5 \mathrm{dpf}$ embryos showing that ventral but not dorsal RGC axons map aberrantly in the tectum after Sema3D knock-down. Left eyes were injected, and right tectum is shown. $G$ is conM0-injected embryo and $H-J$ are $3 D M 0$ injected. Ventral $R G C$ axons (red) extend aberrantly into ventral tectum after 3DM0 injection, but dorsal RGC axons (green) extend into their normal target, the ventral tectum. Scale bar, $50 \mu \mathrm{m}$. 


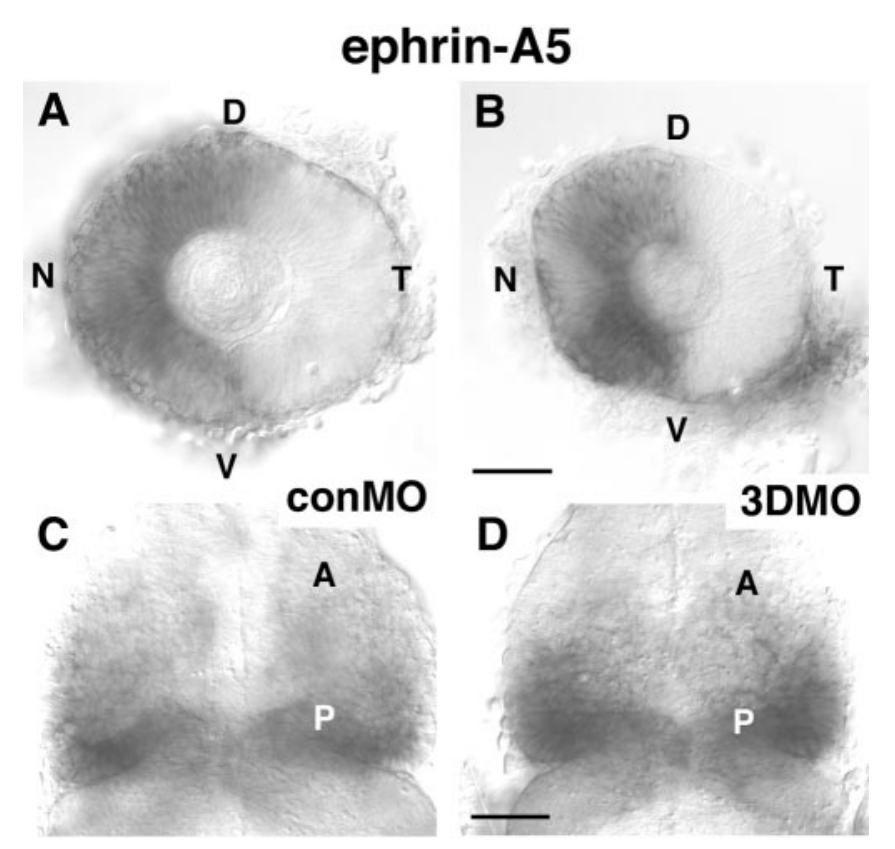

ephrin-B2

E
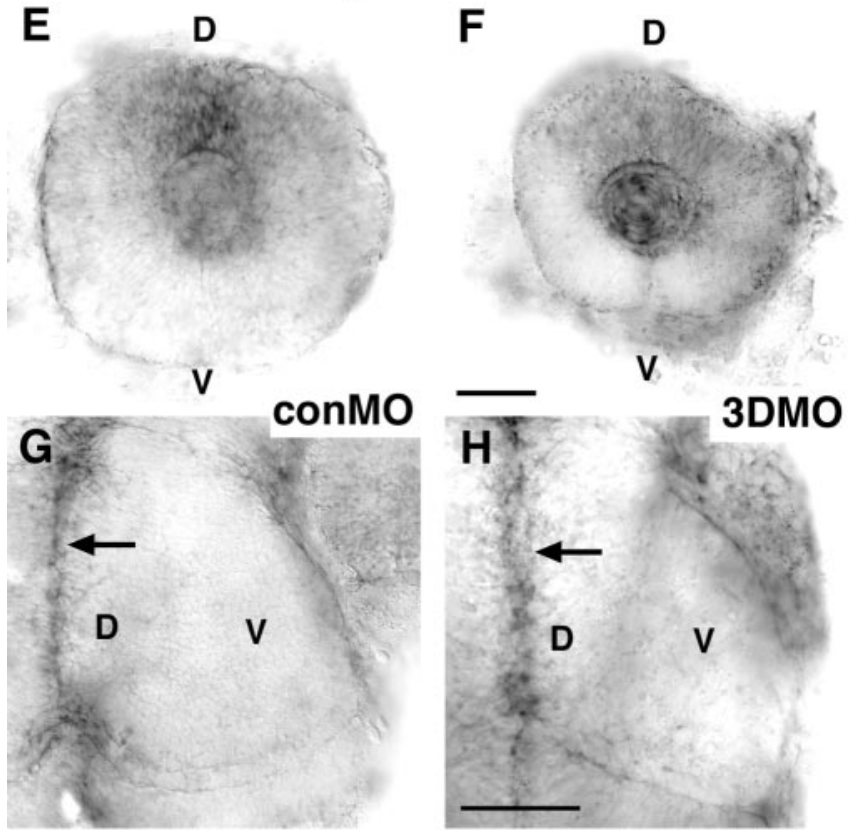

Figure 6. ephrin expression is normal after Sema $3 D$ knock-down. $A-D$, In situ hybridization for ephrin-A5. $A, B$, Lateral views of eyes of $48 \mathrm{hpf}$ conM0-injected $(A)$ and 3DM0-injected $(B)$ embryos. ephrin- $A 5$ is expressed normallly in the nasal retina (and in lens) in both conMO- and 3DM0-injected embryos. N, Nasal; T, temporal; D, dorsal; V, ventral. C, D, Dorsal views of the midbrain of $48 \mathrm{hpf}$ conM0-injected ( $C$ and 3DM0-injected $(D)$ embryos showing ephrin- $A 5$ normal expression in the posterior tectum. $A$, Anterior; $\mathrm{P}$, posterior. $E-H$, In situ hybridization for ephrin-B2. E, $F$, Lateral views of eyes of $48 \mathrm{hpf}$ conM0-injected $(E)$ and 3DM0-injected $(F)$ embryos showing that ephrin- $B 2$ is expressed normally in the dorsal retina (and the lens). $G, H$, Dorsal views of right tectum showing ephrin- $B 2$ expression along dorsal midline of tectum in conMO- and 3DM0-injected embryos. Arrows indicate dorsal midline. Scale bars, $50 \mu \mathrm{m}$.

Because Npn-1 is a receptor component for several class 3 semaphorins including Sema3D, its presence in the RGCs could indicate that RGC axons are guided by a semaphorin other than Sema3D. Sema3A, another class 3 semaphorin that binds Npn-1, is expressed in the zebrafish and Xenopus tectum (Yee et al., 1999; Campbell et al., 2001), and Sema3A repulses Xenopus RCG
A
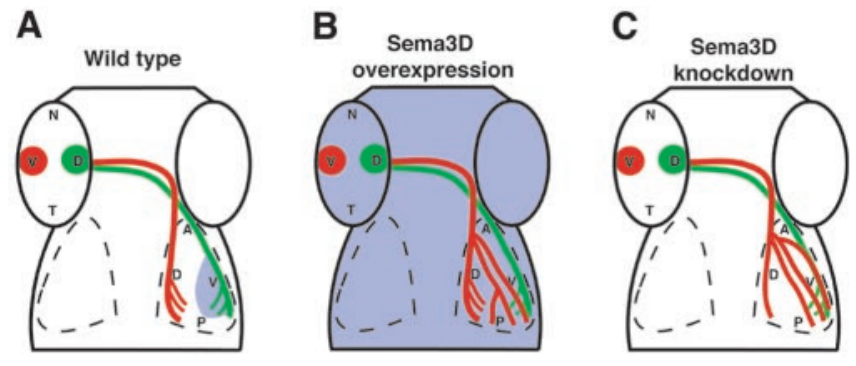

Figure 7. Schematic summary of Sema3D manipulation results. Schematic dorsal views of wild-type $(A)$, Sema3D-overexpressing $(B)$, and Sema3D M0-injected ( $C$ embryos. Sema3D expression is represented in blue. $A$, In wild-type embryos, Sema3D expression in the ventral tectum inhibits ventral retinal axons (red) from invading ventral tectum. $B$, When Sema3D is overexpressed uniformly, most ventral retinal axons extend correctly; however, their arbors also are spread into the ventral tectum. C, When Sema3D is knocked down, many ventral retinal axons extend into the ventral tectum, indicating the loss of an inhibitory cue there.

growth cones in vitro in a stage-dependent manner (Campbell et al., 2001). However, Sema3A has not been shown to act in retinotectal mapping in Xenopus, and zebrafish retinal growth cones are not obviously affected by Sema3A overexpression in vivo (Shoji et al., 1998), suggesting that it is not sufficient to affect retinotectal mapping. It remains possible, however, that Sema3A and Sema3D act redundantly to guide retinotectal targeting in vivo. Another class 3 semaphorin that binds Npn-1, Sema3E, causes collapse of chick RGC growth cones in vitro and is expressed in retinal layers avoided by RGC axons (Steinbach et al., 2002). Thus, Sema3E has been implicated in intraretinal guidance but not retinotectal targeting. Finally, a transmembrane class 5 semaphorin, Sema5A, is expressed along the optic nerve in mice and is thought to provide an inhibitory sheath to prevent axons from straying out of the optic nerve (Oster et al., 2003). Expression of Sema5A in the tectum has not been reported, suggesting that its function may be restricted to guidance in the optic nerve. It is possible that, in our ubiquitous misexpression experiments, Sema3D is acting indirectly by competing with other class 3 semaphorins for Npn-1 binding and thereby disrupting their function. However, in our mosaic misexpression experiments, randomly positioned cells ectopically expressing Sema3D were avoided by RGC axons, suggesting that misexpressed Sema3D is capable of affecting RGC axons directly.

The results of our experiments manipulating Sema3D expression demonstrate that ventral as opposed to dorsal RGC axons are specifically responsive to Sema3D. We show that, beginning at early stages of their outgrowth, ventral RGC axon growth is delayed by Sema3D misexpression, whereas dorsal RGC axons are unaffected. The delay indicates that ventral RGC axons either slow or transiently stop growth when confronted with uniform high Sema3D expression, consistent with an inhibitory activity of Sema3D on these axons. Our mosaic misexpression results also support this idea. Ventral RGC axons that encountered individual cells misexpressing Sema3D stopped growth or diverted their pathway away from the cells. We propose that the differential responsiveness between dorsal and ventral RGC axons reflects a role for Sema3D in retinotectal mapping along the dorsoventral axis of the tectum and, specifically, that Sema3D expression in the ventral tectum inhibits ventral RGC axons from entering this domain, thus forcing them to invade their appropriate target, the dorsal tectum. This model is supported by our data (summarized in Fig. 7) showing that morpholino knock-down of Sema3D resulted in ventral retinal axon growth into the ventral tectum. This result would be expected after the loss of an inhibitory cue in the 
ventral tectum. Interestingly, we also observed some ventral retinal axon growth into the ventral tectum after ubiquitous Sema3D misexpression, although the effect was less severe than after Sema3D knock-down. One potential explanation for this result is that ventral RGC axons are guided normally by the specific pattern of Sema3D expression in the tectum and that this pattern was disrupted by uniform Sema3D misexpression throughout the tectum, causing an effect similar to a loss-offunction phenotype. Others have shown that, in some cases, axons normally guided by a signal present in a gradient or border will not be properly guided when encountering uniform expression of the signal. For example, a gradient of Sema3A is proposed to regulate cortical neurite orientation, which is disrupted in a similar manner by either ubiquitous Sema3A misexpression or Sema3A knock-out (Polleux et al., 1998). Similarly, temporal retinal axons presented with a choice of anterior versus posterior tectal membranes in the in vitro stripe assay are inhibited from growth on the posterior membranes (Walter et al., 1990). However, if the same axons are presented with a uniform substrate of posterior tectal membranes, they will extend on those membranes. Our data suggest that disruption of the Sema3D gradient by uniform misexpression results in loss of some guidance information for the ventral RGC axons, allowing their arborization domain to spread into the ventral tectum.

The inhibitory activity of Sema3D in ventral tectum complements the attractive activity of ephrin-Eph interactions known to guide RGC axons along the dorsoventral axis of the tectum (Hindges et al., 2002; Mann et al., 2002). The fact that we see ventral RGC axons extending into the ventral tectum after disruption of the Sema3D expression pattern suggests there is also an attractive factor for these axons in the ventral tectum that is "unmasked" by Sema3D disruption. Mann et al. (2002) demonstrated that EphB1 in the ventral tectum acts via reverse signaling to attract ephrinB-expressing dorsal retinal axons. Axons of the ventral retina express only low levels of ephrinBs and normally are not attracted to the ventral tectum. Our results suggest that these axons also are also guided by active repulsion from the ventral tectum by Sema3D. When the Sema3D pattern is eliminated and no longer providing guidance information to ventral axons, the low levels of ephrinBs on these axons may be sufficient to attract them to the ventral tectum. Interestingly, our Sema3D knock-down phenotype was more severe than the ubiquitous misexpression phenotype: in some cases, ventral RGC axons extended into the ventral but not dorsal tectum after knock-down. This compares with ventral RGC axons extending to both dorsal and ventral tectum after ubiquitous Sema3D misexpression. Thus, in the absence of Sema3D, there may actually be a strong attraction to the ventral tectum, whereas in uniform Sema3D expression, there may be a weaker attraction. This raises the possibility that Sema3D may influence the ability of the axons to respond to such an attractive signal from the ventral tectum. Because ephrin-Eph reverse signaling can attract RGC axons, this signaling system is an attractive candidate for modulation by Sema3D. At any rate, our study supports the idea that retinotectal mapping along the dorsoventral axis of the tectum is accomplished by a combination of attractive ephrin-Eph interactions and repulsive effects mediated by Sema3D. Furthermore, this work provides the first indication that secreted signaling molecules act with membrane-bound cues to guide retinotectal axons.

Interestingly, Sema3D is also expressed in the region of the optic chiasm when RGC axons cross the midline, before reaching the tectum (Halloran et al., 1999). The function of Sema3D here is not yet known, but one possibility is that Sema3D may act to temporarily stop or slow RGC growth cones at the midline to allow for changes such as increases or decreases in sensitivity to other guidance cues. In support of this idea, live imaging of zebrafish RGC growth cones in vivo showed that growth cones extended more slowly and lingered in the midline region (Hutson and Chien, 2002). The potential relationship between Sema3D signaling at the midline optic chiasm and in retinotectal mapping awaits additional study.

\section{References}

Brennan C, Monschau B, Lindberg R, Guthrie B, Drescher U, Bonhoeffer F, Holder N (1997) Two Eph receptor tyrosine kinase ligands control axon growth and may be involved in the creation of the retinotectal map in the zebrafish. Development 124:655-664.

Brown A, Yates PA, Burrola P, Ortuno D, Vaidya A, Jessell TM, Pfaff SL, O’Leary DD, Lemke G (2000) Topographic mapping from the retina to the midbrain is controlled by relative but not absolute levels of EphA receptor signaling. Cell 102:77-88.

Burrill JD, Easter Jr SS (1995) The first retinal axons and their microenvironment in zebrafish: cryptic pioneers and the pretract. J Neurosci 15:2935-2947.

Campbell DS, Regan AG, Lopez JS, Tannahill D, Harris WA, Holt CE (2001) Semaphorin 3A elicits stage-dependent collapse, turning, and branching in Xenopus retinal growth cones. J Neurosci 21:8538-8547.

Chan J, Mably JD, Serluca FC, Chen JN, Goldstein NB, Thomas MC, Cleary JA, Brennan C, Fishman MC, Roberts TM (2001) Morphogenesis of prechordal plate and notochord requires intact Eph/ephrin B signaling. Dev Biol 234:470-482.

Chen H, Chedotal A, He Z, Goodman CS, Tessier-Lavigne M (1997) Neuropilin-2, a novel member of the neuropilin family, is a high affinity receptor for the semaphorins Sema E and Sema IV but not Sema III. Neuron 19:547-559.

Cox KH, DeLeon DV, Angerer LM, Angerer RC (1984) Detection of mrnas in sea urchin embryos by in situ hybridization using asymmetric RNA probes. Dev Biol 101:485-502.

Ekker SC, Larson JD (2001) Morphant technology in model developmental systems. Genesis 30:89-93.

Feiner L, Koppel AM, Kobayashi H, Raper JA (1997) Secreted chick semaphorins bind recombinant neuropilin with similar affinities but bind different subsets of neurons in situ. Neuron 19:539-545.

Feldheim DA, Kim YI, Bergemann AD, Frisen J, Barbacid M, Flanagan JG (2000) Genetic analysis of ephrin-A2 and ephrin-A5 shows their requirement in multiple aspects of retinocollicular mapping. Neuron 25:563-574.

Frisen J, Yates PA, McLaughlin T, Friedman GC, O’Leary DD, Barbacid M (1998) Ephrin-A5 (AL-1/RAGS) is essential for proper retinal axon guidance and topographic mapping in the mammalian visual system. Neuron 20:235-243.

Fujisawa H, Takagi S, Hirata T (1990) Cell surface molecule A5: a putative involvement in retinal central connection. Neurosci Res Suppl 13:S11-S17.

Goodhill GJ, Richards LJ (1999) Retinotectal maps: molecules, models and misplaced data. Trends Neurosci 22:529-534.

Halloran MC, Severance SM, Yee CS, Gemza DL, Kuwada JY (1998) Molecular cloning and expression of two novel zebrafish semaphorins. Mech Dev 76:165-168.

Halloran MC, Severance SM, Yee CS, Gemza DL, Raper JA, Kuwada JY (1999) Analysis of a zebrafish semaphorin reveals potential functions in vivo. Dev Dyn 214:13-25.

Halloran MC, Sato-Maeda M, Warren JT, Su F, Lele Z, Krone PH, Kuwada JY, Shoji W (2000) Laser-induced gene expression in specific cells of transgenic zebrafish. Development 127:1953-1960.

He Z, Tessier-Lavigne M (1997) Neuropilin is a receptor for the axonal chemorepellent Semaphorin III. Cell 90:739-751.

Hindges R, McLaughlin T, Genoud N, Henkemeyer M, O’Leary DD (2002) EphB forward signaling controls directional branch extension and arborization required for dorsal-ventral retinotopic mapping. Neuron 35:475-487.

Hutson LD, Chien CB (2002) Pathfinding and error correction by retinal axons: the role of astray/robo2. Neuron 33:205-217.

Kawakami A, Kitsukawa T, Takagi S, Fujisawa H (1996) Developmentally 
regulated expression of a cell surface protein, neuropilin, in the mouse nervous system. J Neurobiol 29:1-17.

Kimmel CB, Ballard WW, Kimmel SR, Ullmann B, Schilling TF (1995) Stages of embryonic development of the zebrafish. Dev Dyn 203:253-310.

Kolodkin AL (1998) Semaphorin-mediated neuronal growth cone guidance. Prog Brain Res 117:115-132.

Kolodkin AL, Levengood DV, Rowe EG, Tai YT, Giger RJ, Ginty DD (1997) Neuropilin is a semaphorin III receptor. Cell 90:753-762.

Lee P, Goishi K, Davidson AJ, Mannix R, Zon L, Klagsbrun M (2002) Neuropilin-1 is required for vascular development and is a mediator of VEGF-dependent angiogenesis in zebrafish. Proc Natl Acad Sci USA 99:10470-10475.

Luo Y, Shepherd I, Li J, Renzi MJ, Chang S, Raper JA (1995) A family of molecules related to collapsin in the embryonic chick nervous system. Neuron [Erratum (1995) 15:1218] 14:1131-1140.

Mann F, Ray S, Harris W, Holt C (2002) Topographic mapping in dorsoventral axis of the Xenopus retinotectal system depends on signaling through ephrin-B ligands. Neuron 35:461-473.

Mark MD, Lohrum M, Puschel AW (1997) Patterning neuronal connections by chemorepulsion: the semaphorins. Cell Tissue Res 290:299-306.

McLaughlin T, Hindges R, Yates PA, O'Leary DD (2003) Bifunctional action of ephrin-B1 as a repellent and attractant to control bidirectional branch extension in dorsal-ventral retinotopic mapping. Development 130:2407-2418

Monnier PP, Sierra A, Macchi P, Deitinghoff L, Andersen JS, Mann M, Flad M, Hornberger MR, Stahl B, Bonhoeffer F, Mueller BK (2002) RGM is a repulsive guidance molecule for retinal axons. Nature 419:392-395.

Monschau B, Kremoser C, Ohta K, Tanaka H, Kaneko T, Yamada T, Handwerker C, Hornberger MR, Loschinger J, Pasquale EB, Siever DA, Verderame MF, Muller BK, Bonhoeffer F, Drescher U (1997) Shared and distinct functions of RAGS and ELF-1 in guiding retinal axons. EMBO J $16: 1258-1267$.

Nakamoto M, Cheng H-J, Friedman GC, McLaughlin T, Hansen MJ, Yoon CH, O'Leary DDM, Flanagan JG (1996) Topographically specific effects of ELF-1 on retinal axon guidance in vitro and retinal axon mapping in vivo. Cell 86:755-766.

Nasevicius A, Ekker SC (2000) Effective targeted gene "knockdown" in zebrafish. Nat Genet 26:216-220.

O’Leary DDM, Yates PA, McLaughlin T (1999) Molecular development of sensory maps: representing sights and smells in the brain. Cell 96:255-269.

Oster SF, Bodeker MO, He FL, Sretavan DW (2003) Invariant Sema5A inhibition serves an ensheathing function during optic nerve development. Development 130:775-784.

Polleux F, Giger RJ, Ginty DD, Kolodkin AL, Ghosh A (1998) Patterning of cortical efferent projections by semaphorin-neuropilin interactions. Science 282:1904-1906.
Raper JA (2000) Semaphorins and their receptors in vertebrates and invertebrates. Curr Opin Neurobiol 10:88-94.

Shoji W, Yee C, Kuwada J (1998) Zebrafish Semaphorin Z1a collapses specific growth cones and alters their pathway in vivo. Development 125:1275-1283

Shoji W, Isogai S, Sato-Maeda M, Obinata M, Kuwada JY (2003) Semaphorin3a1 regulates angioblast migration and vascular development in zebrafish embryos. Development 130:3227-3236.

Stahl B, Muller B, von Boxberg Y, Cox EC, Bonhoeffer F (1990) Biochemical characterization of a putative axonal guidance molecule of the chick visual system. Neuron 5:735-743.

Steinbach K, Volkmer H, Schlosshauer B (2002) Semaphorin 3E/ collapsin-5 inhibits growing retinal axons. Exp Cell Res 279:52-61.

Stuermer CA (1988) Retinotopic organization of the developing retinotectal projection in the zebrafish embryo. J Neurosci 8:4513-4530.

Takagi S, Tsuji T, Amagai T, Takamatsu T, Fujisawa H (1987) Specific cell surface labels in the visual centers of Xenopus laevis tadpole identified using monoclonal antibodies. Dev Biol 122:90-100.

Takagi S, Kasuya Y, Shimizu M, Matsuura T, Tsuboi M, Kawakami A, Fujisawa H (1995) Expression of a cell adhesion molecule, neuropilin, in the developing chick nervous system. Dev Biol 170:207-222.

Takahashi T, Fournier A, Nakamura F, Wang LH, Murakami Y, Kalb RG, Fujisawa H, Strittmatter SM (1999) Plexin-neuropilin-1 complexes form functional semaphorin-3A receptors. Cell 99:59-69.

Tamagnone L, Artigiani S, Chen H, He Z, Ming GI, Song H, Chedotal A, Winberg ML, Goodman CS, Poo M, Tessier-Lavigne M, Comoglio PM (1999) Plexins are a large family of receptors for transmembrane, secreted, and GPI-anchored semaphorins in vertebrates. Cell 99:71-80.

Walkenhorst J, Dutting D, Handwerker C, Huai J, Tanaka H, Drescher U (2000) The EphA4 receptor tyrosine kinase is necessary for the guidance of nasal retinal ganglion cell axons in vitro. Mol Cell Neurosci 16:365-375.

Walter J, Muller B, Bonhoeffer F (1990) Axonal guidance by an avoidance mechanism. J Physiol (Paris) 84:104-110.

Winberg ML, Noordermeer JN, Tamagnone L, Comoglio PM, Spriggs MK, Tessier-Lavigne M, Goodman CS (1998) Plexin A is a neuronal semaphorin receptor that controls axon guidance. Cell 95:903-916.

Xu Q, Holder N, Patient R, Wilson SW (1994) Spatially regulated expression of three receptor tyrosine kinase genes during gastrulation in the zebrafish. Development 120:287-299.

Yamada T, Okafuji T, Ohta K, Handwerker C, Drescher U, Tanaka H (2001) Analysis of ephrin-A2 in the chick retinotectal projection using a function-blocking monoclonal antibody. J Neurobiol 47:245-254.

Yee CS, Chandrasekhar A, Halloran MC, Shoji W, Warren JT, Kuwada JY (1999) Molecular cloning, expression, and activity of zebrafish semaphorin Z1a. Brain Res Bull 48:581-593. 